\title{
Labyrinthine window rupture as a cause of acute sensorineural hearing loss
}

\author{
Tomoyuki Nagai $\cdot$ Midori Nagai
}

Received: 3 November 2010 / Accepted: 15 March 2011 / Published online: 30 March 2011

(C) The Author(s) 2011. This article is published with open access at Springerlink.com

\begin{abstract}
Labyrinthine window rupture (LWR) is one cause of acute sensorineural hearing loss and need for early exploration is clear for good improved hearing. Acute sensorineural hearing loss of $60 \mathrm{~dB}$ or more treated from May 2006 to May 2010 were retrospectively analyzed. There were 21 ears of severe deafness, 18 ears of profound deafness, and 10 ears of total deafness. All patients were examined with temporal bone CT. Space-occupying lesions around the labyrinthine windows were suggestive images of LWR. Thirty-five ears were operated for LWR while 14 ears of SHL received conservative treatments. Fifty-seven percent of LWR improved $30 \mathrm{~dB}$ or more after sealing of both labyrinthine windows. Of the 15 markedly recovered ears, 14 ears were operated within 2 weeks from the onset. Of the five cured ears, four ears were operated within a week from the onset. As for the hearing prognosis of SHL, $88 \%$ of severe and profound deafness improved $30 \mathrm{~dB}$ or more but total deafness did not improve more than $30 \mathrm{~dB}$. Exclusion of LWR from SHL and early surgical intervention in LWR will bring about good hearing prognosis to both LWR and SHL.
\end{abstract}

\footnotetext{
T. Nagai $(\square)$

Department of Otolaryngology, National Hospital Organization,

Miyakonojo Hospital, Iwayoshi 5033-1, Miyakonojo,

Miyazaki 885-0014, Japan

e-mail: nagait@miyakonojo.hosp.go.jp

M. Nagai

Department of Speech-Language-Hearing Therapy,

Kyushu University of Health and Welfare,

1714-1 Yoshino, Nobeoka, Miyazaki 882-0072, Japan

e-mail: nagai-tmn@mc2.seikyou.ne.jp
}

Keywords Perilymphatic fistula $\cdot \mathrm{CT} \cdot$ Ear surgery . Hearing result $\cdot$ Sudden hearing loss

\section{Introduction}

Most of the acute sensorineural hearing loss is universally diagnosed as sudden hearing loss (SHL). However, the pathogenesis of SHL remains unknown and proposed theories include vascular occlusion, membrane brakes, and viral cochleitis [1]. Treatment of SHL is widely variable but no valid randomized controlled trial exists to determine effective treatment of SHL [2-4].

Labyrinthine window rupture (LWR) is one cause of acute sensorineural hearing loss and mimics SHL [5-12]. Exploratory tympanotomy for SHL with inspection and sealing of the labyrinthine windows is therapeutic option if conservative treatment for SHL fails to improve the hearing level [6-12]. However, early surgical intervention appears to be rewarded with good hearing recovery $[8,9,11]$. One reason for preferring conservative treatment at the early stage is absence of diagnostic tests for LWR. Therefore, new noninvasive diagnostic tools must be developed to improve the management of LWR [13].

LWR is a condition that allows the egress of perilymph from the inner ear to the middle ear. Temporal bone CT can detect even a small amount of fluid in middle ear cavity. Fourteen out of 16 cases were true LWR when CT showed more than one-third of their round window recess was filled up with fluid [14]. Air fluid level in the middle ear documented by CT is a suggestive image of LWR [15]. Therefore, we have utilized CT to make diagnose of LWR since 2006. Exclusion of LWR from SHL and early surgical intervention in LWR have improved hearing prognosis of both LWR and SHL. 


\section{Materials and methods}

A retrospective review was made of 48 patients, seen between May 2006 and May 2010, who attended the Miyakonojo Hospital with symptoms of a rapid loss of hearing of $60 \mathrm{~dB}$ or more. Twenty-four patients had been treated with corticosteroid before attending the Miyakonojo Hospital. The severity of hearing loss was evaluated with the average hearing level at five frequencies $(250 \mathrm{~Hz}$, $500 \mathrm{~Hz}, 1 \mathrm{kHz}, 2 \mathrm{kHz}, 4 \mathrm{kHz}$ ) on the pure tone audiogram. The severity was categorized into three grades: severe deafness $(60-89 \mathrm{~dB})$, profound deafness $(90-110 \mathrm{~dB})$ and total deafness $(111 \mathrm{~dB})$ that was no response on audiometry at all frequencies.

All patients were examined with dual slice CT scanner of a G.E. Hi speed NX/is (General Electronic, Milwaukee, WI, USA). All but one patient underwent CT examination on the same day of their hospital attendance. Standard temporal bone $\mathrm{CT}$ was performed in the axial projection with a bone algorithm. Slices were $1 \mathrm{~mm}$ thick and contiguous. The images were carefully surveyed whether there was any space-occupying lesion in the tympanic sinus (Figs. 1, 2, 3) or in the round window recess (Figs. 4, 5, 6).

Our indications for exploratory tympanotomy were same to literatures [9-12]. They were progressive hearing loss, acute hearing loss with vertigo and acute hearing loss with

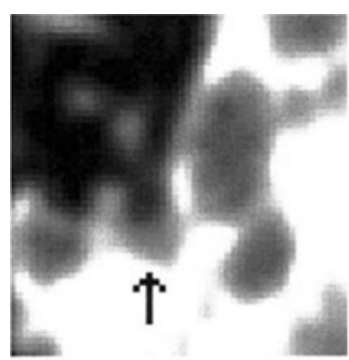

right

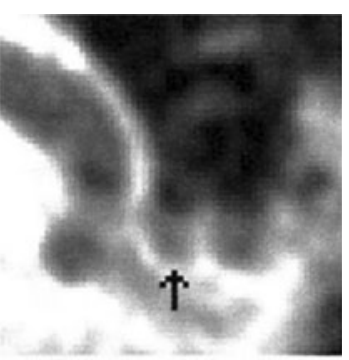

left
Fig. 1 Axial CT shows air fluid level in the tympanic sinus (arrow)

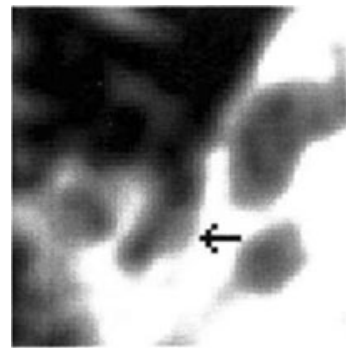

right

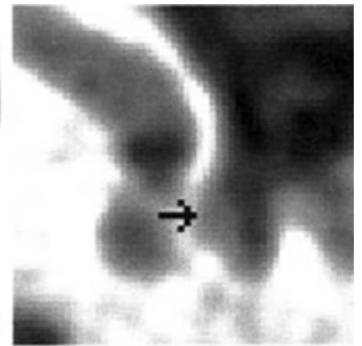

left
Fig. 2 Axial CT shows hemispherical lesion on the sidewall of the tympanic sinus (arrow)

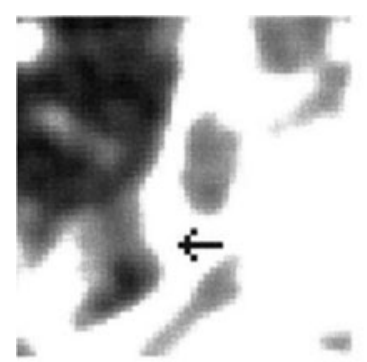

right

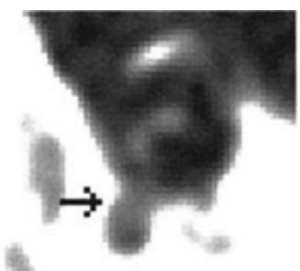

left

Fig. 3 Axial CT shows space-occupying lesion at the orifice of the tympanic sinus (arrow)

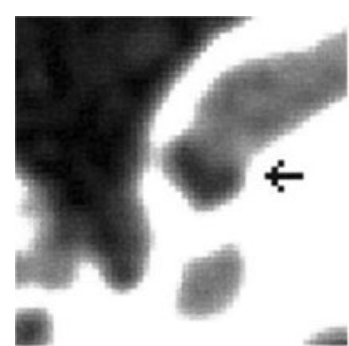

right

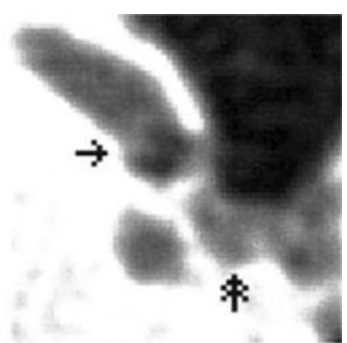

left

Fig. 4 Axial CT shows focal bulging of the round window membrane (arrow). Double arrow shows air fluid level over the orifice of the left tympanic sinus
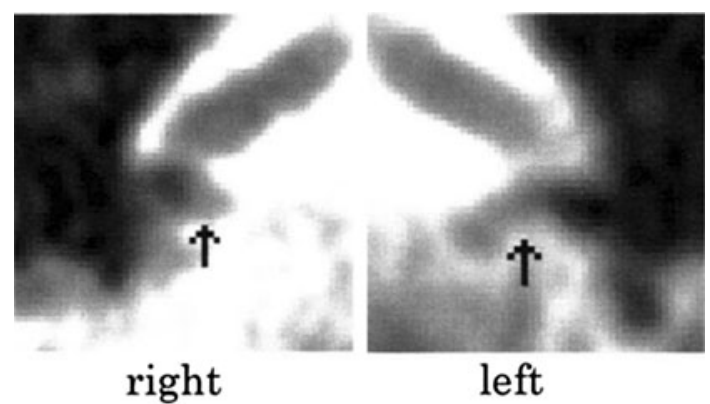

Fig. 5 Axial CT shows space-occupying lesion in the round window recess (arrow)

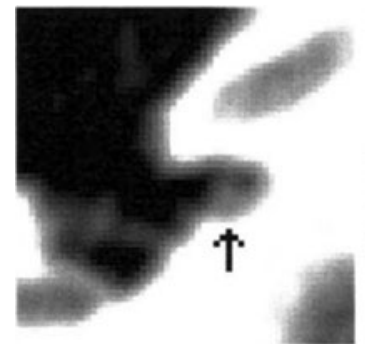

right

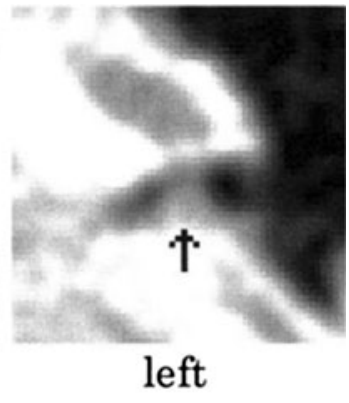

Fig. 6 Axial CT shows hemispherical lesion in the round window recess (arrow) 
the presence of positional nystagmus in a spine position. Space-occupying lesions around the labyrinthine windows were a pre-condition for exploratory tympanotomy.

Thirty-five ears of 34 patients who made the decision to have exploratory tympanotomy were operated for LWR. There were 19 males and 15 females in the patient group. Subjects ranged in age from 9 to 80 years. The median age was 47.4 years.

Sixteen ears of LWR were severe deafness, 15 ears were profound deafness and four ears were total deafness. Nine patients had vertigo and nine patients had balance disturbance. There was a positive history of antecedent head trauma in nine patients 3 months to 38 years before. Seven patients had a recent history of heavy lifting or straining. Nose blowing was in four patients and exposure to loud sound was in two patients. Past history of SHL was in one patient.

Length of time from CT examination to exploratory tympanotomy was $1-8$ days (Table 1 ). The median time interval was 2.1 days. Length of time from initiation of hearing loss to exploratory tympanotomy was 1-26 days. The median time interval was 8.5 days.

Exploratory tympanotomy was performed by post auricular incision under general anesthesia. Annular bone removal was done with a currete. The oval and round windows recesses were then examined for perilymphatic leaks. An oval window leak was seen in nine ears, a round window leak in three ears and leakage from both oval and round windows in 23 ears. A large quantity of leak was seen in $57 \%$ of the ears and a small quantity of leak was seen in $43 \%$ of the ears. Displacement of the stapes footplate was not encountered. Both labyrinthine window recesses were packed with the temporalis fascia supported laterally by Gelfoam. Neither corticosteroid nor dextrane was used for post-operative treatment.

Fourteen patients were diagnosed as having SHL and received conservative treatments. However, there was a positive history of antecedent head trauma in four patients 10 days to 20 years before the onset. One patient had an event of heavy lifting 3 days before the onset. Two patients

Table 1 Number of ears related to time intervals from CT to surgery in 35 ears of LWR of total deafness, who had positive findings in temporal bone CT, did not agree to have exploratory tympanotomy. There were ten males and four females in patient group. Subjects ranged in age from 21 to 84 years. The median age was 61.6 years.

Five ears were severe deafness and 3 ears were profound deafness. They had neither vertigo nor balance disturbance. Two patients respectively received total $110 \mathrm{mg}$ or $40 \mathrm{mg}$ of oral prednisone. Four patients received oral adenosine triphosphoric disodium hydrate.

Six ears were total deafness. One patient had vertigo and five patients had balance disturbance. Two patients were treated with $125 \mathrm{mg}$ of methylprednisolone sodium succinate intravenously on 3 days followed by a course of $25-\mathrm{mg}$ prednisolone tapered over 11 days. One patient received total $135 \mathrm{mg}$ of oral prednisone. Three patients received oral adenosine triphosphoric disodium hydrate.

Improvement in hearing was categorized into five grades. Grade "cured" is all five frequencies within normal level or recovery to the same level of the other ear. Grade "markedly recovered" is the improvement of $30 \mathrm{~dB}$ or more. Grade "slightly recovered" is the improvement of $10 \mathrm{~dB}$ or more but $<30 \mathrm{~dB}$. Grade "unchanged" is the improvement of $<10 \mathrm{~dB}$. Grade "worsened" is decline of $10 \mathrm{~dB}$ or more.

\section{Results}

The hearing prognosis of LWR was analyzed according to the severity of hearing loss (Table 2). Fifty percent of severe deafness and $73 \%$ of profound deafness were cured or markedly recovered. Of four ears of total deafness, one ear was markedly recovered.

Lower frequencies tended to recover more favorably than higher frequencies. Ten of the 15 markedly recovered ears and 3 of the 10 slightly recovered ears showed an abruptly falling audiometric configuration [7]. Hearing loss did not return to normal where high and middle frequencies in the audiogram obtained just before the surgery were scale out.

\begin{tabular}{lc}
\hline $\begin{array}{l}\text { Days from } \\
\text { CT to surgery }\end{array}$ & $\begin{array}{l}\text { Number } \\
\text { of ears }\end{array}$ \\
\hline 1 & 20 \\
2 & 7 \\
3 & 2 \\
4 & 3 \\
5 & 1 \\
7 & 1 \\
8 & 1 \\
\hline
\end{tabular}

Table 2 Recovery related to severity of hearing loss in 35 ears of LWR

\begin{tabular}{|c|c|c|c|c|c|}
\hline $\begin{array}{l}\text { Severity of } \\
\text { hearing loss }(\mathrm{dB})\end{array}$ & Cured & $\begin{array}{l}\text { Markedly } \\
\text { recovered }\end{array}$ & $\begin{array}{l}\text { Slightly } \\
\text { recovered }\end{array}$ & Unchanged & Worsened \\
\hline Severe (60-89) & 3 & 5 & 5 & 3 & \\
\hline $\begin{array}{l}\text { Profound } \\
\qquad(90-110)\end{array}$ & 2 & 9 & 3 & & 1 \\
\hline Total (111) & & 1 & 2 & 1 & \\
\hline
\end{tabular}


The hearing prognosis of LWR was affected by the time of surgery (Table 3). Of the 15 markedly recovered ears, 14 ears were operated within 2 weeks from the onset. Of the five cured ears, four ears were operated within a week from the onset.

Six ears were operated within 2 days from the onset (Table 3). Two of them were cured. Three of them with no audiometric response in middle and high frequencies were markedly recovered. The remaining one ear that was total deafness with balance disturbance was unchanged.

Hearing prognosis was analyzed according to both a quantity of leak and time of surgery (Table 4). Thirteen of 19 ears that received the tympanotomy within a week had a large quantity of leak, whereas 7 of 16 ears that underwent the tympanotomy on and after the 8th day had a large quantity of leak. Hearing recovery was observed in greater percentage of patients who underwent the tympanotomy within a week and had a large quantity of leak than patients who had a small quantity of leak. On the contrary, hearing recovery was observed in smaller percentage of patients who underwent the tympanotomy on and after the 8th day and had a large quantity of leak than patients who had a small quantity of leak.

Vertigo and balance disturbance had no influence on their hearing prognosis. Hearing recovery was not affected by positive histories of antecedent head trauma, heavy lifting and straining et al.

The hearing prognosis of SHL was analyzed according to the severity of hearing loss (Table 5). Of five ears of severe deafness, four ears were cured. Of three ears of profound deafness, two ears were cured and one ear was markedly recovered. Six ears of total deafness with vertigo

Table 3 Recovery related to time intervals from onset of symptoms to surgery in 35 ears of LWR

\begin{tabular}{|c|c|c|c|c|c|}
\hline $\begin{array}{l}\text { Days from } \\
\text { onset to surgery }\end{array}$ & Cured & $\begin{array}{l}\text { Markedly } \\
\text { recovered }\end{array}$ & $\begin{array}{l}\text { Slightly } \\
\text { recovered }\end{array}$ & Unchanged & Worsened \\
\hline 1 & & 1 & & & \\
\hline 2 & 2 & 2 & & 1 & \\
\hline $3-7$ & 2 & 6 & 4 & & 1 \\
\hline $8-14$ & 1 & 5 & 3 & 2 & \\
\hline $15-21$ & & 1 & 2 & 1 & \\
\hline 26 & & & 1 & & \\
\hline
\end{tabular}

or balance disturbance were neither cured nor markedly recovered.

\section{Discussion}

There are three criteria to confirm diagnosis of LWR at surgery. They are actual observation of fluid leak [6, 7], direct inspection of the round window membrane rupture [8-11] and no simultaneous pressure transmission from the oval to the round window $[11,12]$. The actual fluid leak in the labyrinthine window recesses was found in $71 \%$ [6] and $40 \%$ [7]. Our result was that a large quantity of leak was seen in $57 \%$ and a small quantity of leak was seen in $43 \%$.

A large quantity of leak was more frequent in ears operated within a week than in ears operated on and after the 8th day. Ears with a large quantity of leak had a tendency toward poor hearing recovery when exploratory tympanotomy was delayed. Temporal bone CT could not predict a quantity of perilymphatic leak. Therefore, ears with spaceoccupying lesions around the labyrinthine windows should be operated early when the patients have suggestive symptoms of LWR.

Arndt [8] carried out 45 exploratory tympanotomy among 63 patients of SHL. Mertens and Rudert [9] performed 39 exploratory tympanotomy among 247 patients of SHL. We operated 35 ears for LWR while we conservatively treated 14 ears of SHL. Incidence of perilymphatic fistula surgery for acute sensorineural hearing loss is very limited in the United States [13]. However, we think LWR might not be a rare cause of acute sensorineural hearing loss.

Indication of exploratory tympanotomy for SHL is progressive hearing loss or no response to conservative treatment [8-12]. A term of conservative treatment is 1 day to 2 weeks [6-12]. Early exploratory tympanotomy is not recommended because it might decrease the chance for inner ear healing and spontaneous remission might occur in the first days [5]. To avoid unnecessary exploratory tympanotomy, we utilize temporal bone CT to detect perilymph in the middle ear cavity. We choose conservative treatment when CT shows no space-occupying lesion around the labyrinthine windows.

Most patients of LWR in literatures are operated within 2 weeks from the onset [9-12]. Recovery rate is better in
Table 4 Hearing recovery related to both a quantity of leak and time intervals from onset of symptoms to surgery

\begin{tabular}{llllll}
\hline $\begin{array}{l}\text { Days from } \\
\text { onset to surgery }\end{array}$ & \multicolumn{2}{l}{ A large quantity of leak } & & \multicolumn{2}{c}{ A small quantity of leak } \\
\cline { 2 - 3 } \cline { 5 - 6 } \cline { 5 - 6 } & $30 \mathrm{~dB}$ and more & Less than $30 \mathrm{~dB}$ & & $30 \mathrm{~dB}$ and more & Less than $30 \mathrm{~dB}$ \\
\hline$\sim 7$ & 10 & 3 & 3 & 3 \\
$8 \sim$ & 2 & 5 & 5 & 4 \\
\hline
\end{tabular}


Table 5 Recovery related to severity of hearing loss in 14 ears of SHL

\begin{tabular}{lllll}
\hline $\begin{array}{l}\text { Severity of } \\
\text { hearing loss }(d B)\end{array}$ & Cured & $\begin{array}{l}\text { Markedly } \\
\text { recovered }\end{array}$ & $\begin{array}{l}\text { Slightly } \\
\text { recovered }\end{array}$ & Unchanged \\
\hline $\begin{array}{l}\text { Severe (60-89) } \\
\text { Profound (90-110) }\end{array}$ & 2 & 1 & 1 & \\
Total (111) & & & 2 & 4 \\
\hline
\end{tabular}

patients operated within the first week than those within the second week [9, 11]. Exploration of the round window should be done within the first few days [8]. Our hearing prognosis related to time of surgery is same to the previous reports.

According to the literatures, complete recovery rate of hearing loss by sealing of the labyrinthine windows is $7 \%$ [8] and $10 \%$ [12]. Our result is $14 \%$. Needed conditions of the complete recovery are both early surgical intervention and detectable hearing loss in middle and high frequencies in the audiogram obtained just before the surgery.

Treatments of LWR are strict bed rest or exploratory tympanotomy with sealing of both round and oval windows [5-13]. Fifty-seven percent of LWR over $60 \mathrm{~dB}$ was either cured or markedly recovered after surgical closure of both labyrinthine windows. If they had received conservative treatments, their hearing prognosis would have been $<50 \%$ [16-18].

Our hearing prognosis of SHL is better than the literatures [16-18]. Eighty-eight percent of severe and profound deafness were cured or markedly recovered. Hearing prognosis of total deafness with vertigo or balance disturbance was not good, which was equal to literatures [16-18].

In conclusion, presence of space-occupying lesion in the tympanic sinus and/or the round window recess strongly supports the diagnosis of true LWR with symptoms suggesting LWR. Since delayed surgery may permit cochlear deterioration, early surgical intervention is needed for excellent postoperative hearing of LWR. Surgical intervention in LWR, that resultantly excludes LWR from SHL, will make hearing prognosis of SHL better than general treatments [2-4].

Acknowledgments I would like to express my sincere thanks to Dr. Takao Kodama, Department of Radiology, Faculty of Medicine, University of Miyazaki, for his valuable suggestions to CT.

Open Access This article is distributed under the terms of the Creative Commons Attribution Noncommercial License which permits any noncommercial use, distribution, and reproduction in any medium, provided the original author(s) and source are credited.

\section{References}

1. Merchant SN, Adams JC, Nadol JB Jr (2005) Pathology and pathophysiology of idiopathic sudden sensorineural hearing loss. Otol Neurotol 26:151-160

2. Conlin AE, Parnes LS (2007) Treatment of sudden sensorineural hearing loss: I. A systematic review. Arch Otolaryngol Head Neck Surg 133:573-581

3. Conlin AE, Parnes LS (2007) Treatment of sudden sensorineural hearing loss: II. A Meta-analysis. Arch Otolaryngol Head Neck Surg 133:582-586

4. Finger RP, Gostian AO (2006) Idiopathic sudden hearing loss: contradictory clinical evidence, placebo effects and high spontaneous recovery rate-where do we stand in assessing treatment outcomes? Acta Otolaryngol 126:1124-1127

5. Simmons FB (1979) The double-membrane break syndrome in sudden hearing loss. Laryngoscope 89:59-66

6. Goodhill V, Brockman SJ, Harris I, Hantz O (1973) Sudden deafness and labyrinthine window ruptures. Audio-vestibular observations. Ann Otol Rhinol Laryngol 82:2-12

7. Kanzaki J (1986) Idiopathic sudden progressive hearing loss and round window membrane rupture. Arch Otorhinolaryngol 243: $158-161$

8. Arndt HJ (1984) Spontaneous perforation of the membrane of the round window-a major cause of sudden deafness? Laryngol Rhinol Otol (Stuttg) 63:439-444

9. Mertens J, Rudert H (1986) Sudden deafness caused by rupture of the round window membrane. Surgical indications, course and prognosis. HNO 34:320-324

10. Tigges G, Stoll W, Schmäl F (2003) Prognostic factors in hearing recovery following sudden unilateral deafness. HNO 51:305-309

11. Maier W, Fradis M, Kimpel S, Schipper J, Laszig R (2008) Results of exploratory tympanotomy following sudden unilateral deafness and its effects on hearing restoration. Ear Nose Throat J 87:438-451

12. Gedlicka C, Formanek M, Ehrenberger K (2009) Analysis of 60 patients after tympanotomy and sealing of the round window membrane after acute unilateral sensorineural hearing loss. Am J Otolaryngol 30:157-161

13. House JW, Morris MS, Kramer SJ, Shasky GL, Coggan BB, Putter JS (1991) Perilymphatic fistula: surgical experience in the United States. Otolaryngol Head Neck Surg 105:51-61

14. Veillon F, Riehm S, Emachescu B, Haba D, Roedlich MN, Greget M, Tongio J (2001) Imaging of the windows of the temporal bone. Semin Utrasound CT MR 22:271-280

15. Zalzal GH, Shott SR, Towbin R, Cotton RT (1986) Value of CT scan in the diagnosis of temporal bone diseases in children. Laryngoscope 96:27-32

16. Byl FM Jr (1984) Sudden hearing loss: eight years' experience and suggested prognostic table. Laryngoscope. 94:647-661

17. Chang NC, Ho KY, Kuo WR (2005) Audiometric patterns and prognosis in sudden sensorineural hearing loss in southern Taiwan. Otolaryngol Head Neck Surg 133:916-922

18. Cvorović L, Deric D, Probst R, Hegemann S (2008) Prognostic model for predicting hearing recovery in idiopathic sudden sensorineural hearing loss. Otol Neurotol 29:464-469 